\title{
Ultrasonic-assisted ruthenium-catalyzed one-pot synthesis of biscoumarins
}

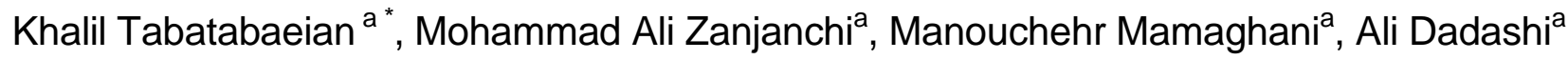

${ }^{a}$ Department of Chemistry, Faculty of Sciences, University of Guilan, P. O. Box: 41335-1914, Iran

"Corresponding author: Taba@guilan.ac.ir

\section{ABSTRACT}

The Ru-grafted zeolite beta was found to be an excellent heterogeneous catalyst for one-pot synthesis of biscoumarins. This reaction was carried out under reflux condition and ultrasonic irradiation. On the other hand, the catalyst could be recovered for the subsequent reactions and reused without appreciable loss of activity.

\section{Indexing terms/Keywords}

Ultrasonic irradiation; heterogeneous catalysis; ruthenium; zeolite beta; schiff-base condensation; biscoumarin.

\section{Council for Innovative Research}

Peer Review Research Publishing System

Journal: Journal of Advances in Chemistry

Vol. 11, No. 2

editorjaconline@gmail.com

www.cirjac.com 


\section{INTRODUCTION}

Ruthenium complexes have been known as versatile and useful catalysts for many organic transformations [1, 2] Although, homogeneous ruthenium catalysts are often very much active and selective producing excellent yields, but difficult separation from the reaction media limits their application [3]. On the other hand immobilization of homogeneous catalysts onto inorganic matrices combines the advantages of homogeneous and heterogeneous catalysis [4]. Ruthenium species supported on a variety of supports such as montmorillonite $\mathrm{K} 10$, polystyrene, $\mathrm{Al}_{2} \mathrm{O}_{3}$, Silica, Micelle templated silica (MTS), MCM-41 and FAU-Y zeolite have been reported in literature [5-13]. Meanwhile zeolite beta with superior physicochemical properties such as large pore size, high silicon to aluminum ratio, high acid strength and thermal stability could be a good framework for the immobilization of a variety of catalytic species. Developing ways to synthesize coumarins has been of considerable interest due to their wide range of biological and therapeutic properties such as anticoagulant, insecticidal, antihelminthic, hypnotic, antifungal, and HIV protease inhibition activities [14-16]. Furthermore, these heterocyclic compounds can be employed as additives to food, cosmetic [17] and optical brightening agents [18]. A number of coumarins are also available from natural sources [19-21]. Biscoumarins, the bridge substituted dimers of 4hydroxycoumarin, have divers biological activities such as anticoagulant [22], antioxidant [23], anticancer [24], cytotoxicity [25], and urease inhibition [26]. Moreover, cytotoxic activity of lanthanum (III) complexes of biscoumarins is reported [27]. Condensation reaction between 4-hydroxycoumarin and various aldehydes in the presence of catalyst is a straightforward approach for the synthesis of biscoumarins. A variety of reagents such as molecular iodine [28], tetrabutylammonium bromide (TBAB) [29], $\mathrm{MnCl}_{2}$ [30], sodium dodecyl sulfate (SDS) [31], $\mathrm{SO}_{3} \mathrm{H}$ functionalized, ionic liquids [32], $\mathrm{Zn}$ (Proline) ${ }_{2}$ [33], 3-methyl-1-(4-sulfonic acid)butylimidazolium hydrogensulfate [ $\left.\mathrm{MIM}\left(\mathrm{CH}_{2}\right)_{4} \mathrm{SO}_{3} \mathrm{H}\right]\left[\mathrm{HSO}_{4}\right]$ [34], Sulfated titania [35], $\mathrm{SiO}_{2} \mathrm{Cl}$ [36] and $\mathrm{Poly}\left(4\right.$-vinylpyridinium) perchlorate $\left[\mathrm{P}(4-\mathrm{VPH}) \mathrm{ClO}_{4}\right.$ ] [37] have been employed to accomplish this transformation. Furthermore, microwave irradiation has been utilized for this synthesis [38, 39]. In spite of the merits of aforementioned routes, some of them suffer from the severe drawbacks, such as long reaction times, tedious work-up procedure and use of expensive and toxic catalysts. Therefore, development of an efficient catalytic system for the synthesis of biscoumarins would be highly desirable. In our previous work, we have reported an efficient method for the synthesis of biscoumarin derivaties using $\mathrm{RuCl}_{3} \cdot \mathrm{nH}_{2} \mathrm{O}$ as a homogeneous catalyst [40]. In an attempt to heterogenize homogeneous ruthenium compounds, recently we have explored an efficient protocol for the synthesis of a new ruthenium bound heterogeneous catalyst through Schiff-base condensation reaction between 3-aminopropyltrethoxysilane (APTES) functionalized zeolite beta and 2- pyridine carbaldehyde followed by complexation with $\mathrm{Ru}(\mathrm{CO})_{4}(\mathrm{Ru} @$ imine-Z) (Scheme 1) [41]. In this study, this functionalized microporous material was used as an effective heterogeneous catalyst for the synthesis of biscoumarins (3a-t) (Scheme 2).

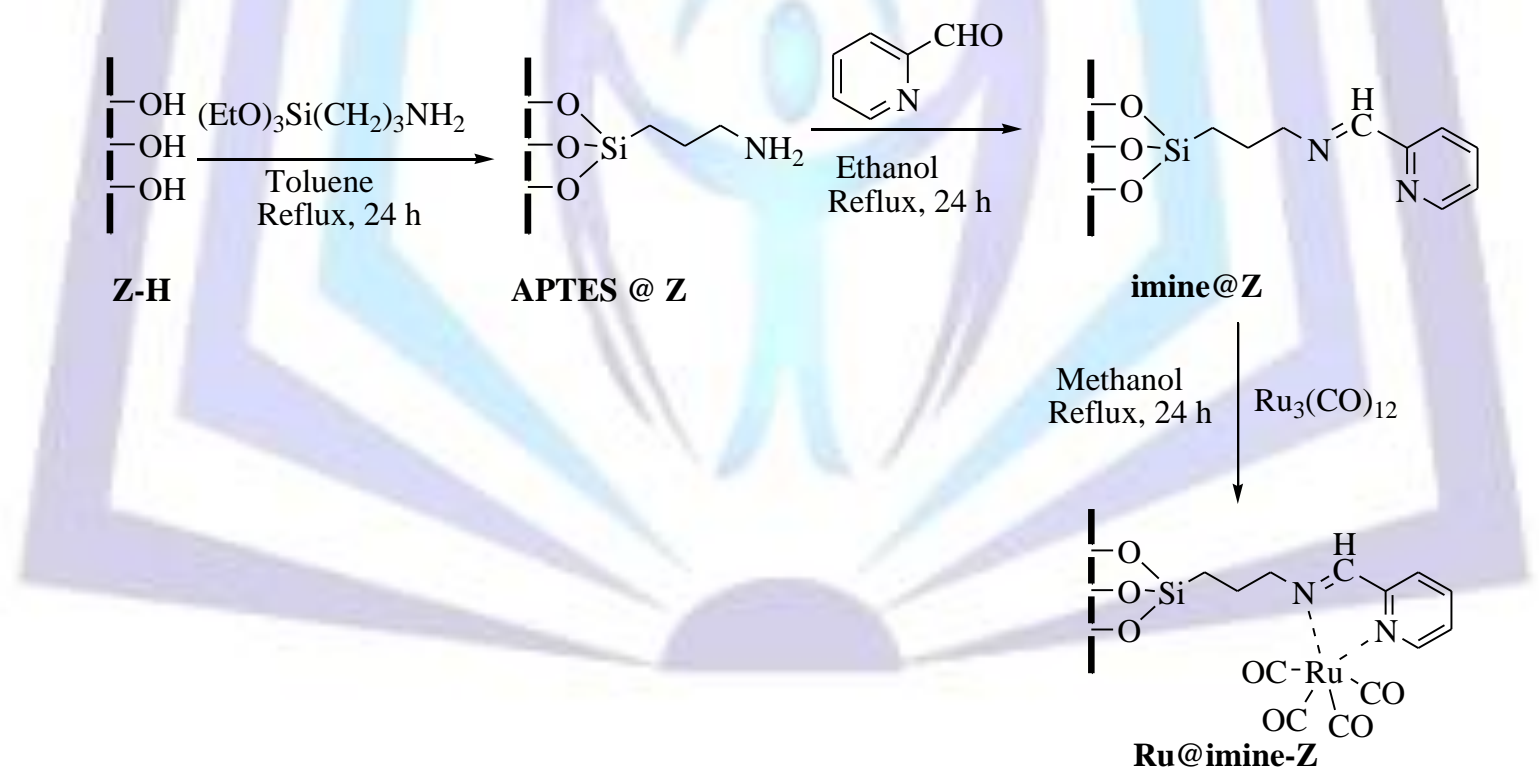

Scheme 1: Immobilization of ruthenium onto imine-functionalized zeolite beta through coordinative attachment<smiles>O=c1cc(O)c2ccccc2o1</smiles>

1

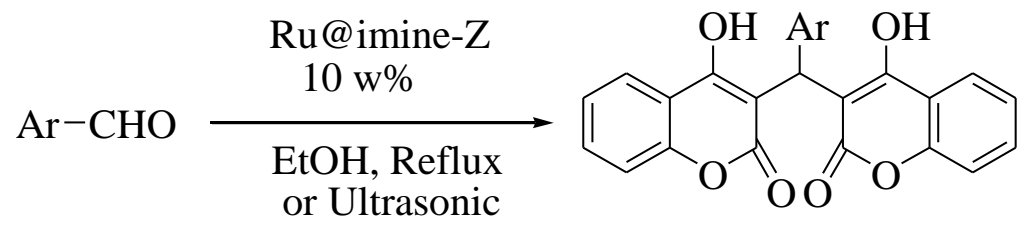

2

3a-t

Scheme 2: Synthesis of biscoumarins in the presence of Ru@imine-Z 


\section{EXPERIMENTAL}

\subsection{Chemicals and apparatus}

All the commercial organic reagents and solvents were purchased from Merck and used without further purification. Tetraethylammonium hydroxide (TEAOH, 20\%), sodium chloride $(99.5 \%)$, potassium chloride (99.5\%) and sodium hydroxide (98\%) were obtained from Merck. Sodium aluminate $\left(56 \mathrm{w} \% \mathrm{Al}_{2} \mathrm{O}_{3}, 37 \mathrm{w} \% \mathrm{Na} \mathrm{O}_{2}\right)$ as alumina source purchased from Technical company. $\mathrm{Ru}_{3}(\mathrm{CO})_{12}(99 \%)$ was purchased from Acros. Degussa aerosil as silica source was used for the synthesis of zeolite beta. Deionized water was used in the present study. XRD patterns were recorded on a Philips PW1840 diffractometer with Cu-Ka radiation $\left(1.5418 \AA\right.$ ), and scan rate $0.1^{\circ} 2 \theta / \mathrm{s}$ and within a range of $2 \theta$ of $4^{\circ}-70^{\circ}$. Scanning electron micrographs were taken on a LEO 1430 VP instrument. The amount of ruthenium content was measured by inductively coupled plasma (ICP; Labtam 8440 plasma lab). The specific surface area based on nitrogen physisorption was determined by Sibata surface area apparatus 1100 . Ultrasound device Astra $3 \mathrm{D}(9.5 \mathrm{~L}, 45 \mathrm{kHz}$ frequency, input power with heating, $305 \mathrm{~W}$, number of transducers, 2) from TECNO-GAZ was used. IR spectra were recorded on a Perkin-Elmer model spectrum one using $\mathrm{KBr}$ plates in the range of $400-4000 \mathrm{~cm}^{-1}$. ${ }^{1} \mathrm{H}$ and ${ }^{13} \mathrm{C}$ NMR spectra were recorded on Bruker Advance spectrometer at 400 and $100 \mathrm{MHz}$, respectively in $\mathrm{CDCl}_{3}$ or $\mathrm{DMSO}_{-} \mathrm{d}_{6} \mathrm{using}$ TMS as an internal standard. Melting points were measured on a BÜCHI Melting point B-540 apparatus and are uncorrected. Elemental analysis (CHN) was performed on Carlo-Erba EA1110 CNNO-S instrument.

\subsection{Catalyst Preparation}

Immobilization of $\mathrm{Ru}_{3}(\mathrm{CO})_{12}$ onto imine-functionalized zeolite $\mathrm{H}$-beta was described in our recent work [41].

\subsection{General procedure for the synthesis of biscoumarin derivatives under thermal conditions}

To a mixture of 4 - hydroxycoumarin $(2 \mathrm{mmol})$ and aldehyde $(1 \mathrm{mmol})$, catalyst $(10 \mathrm{w} \%$ based on all substrates) was added. The mixture was stirred for appropriate time in ethanol $(5 \mathrm{~mL})$ under reflux condition. After completion of the reaction (as evidenced by TLC) and evaporation of ethanol, Ethyl acetate $(20 \mathrm{~mL})$ was added and the mixture was centrifuged to separate the catalyst. The filtrate was concentrated and the crude solid product was recrystallized from ethanol to afford pure product. The recycled catalyst was washed with ethyl acetate and acetone. After being dried it can be reused without further purification. All of the products were known and identified by comparison of their melting points and spectral data with those reported in the literature.

\subsection{Typical procedure for the synthesis of biscoumarins under sonochemical conditions}

To a mixture of 4 - hydroxycoumarin $(2 \mathrm{mmol})$, aldehyde $(1 \mathrm{mmol})$, and ethanol $(2 \mathrm{~mL})$ was added catalyst $(10 \mathrm{w} \%$ based on all substrates) and the reaction mixture was exposed to ultrasonic irradiation at room temperature for appropriate time, as shown in Table 2, entries 1-20. The progress of the reaction was followed by TLC. After completion of the reaction and evaporation of ethanol, Ethyl acetate $(20 \mathrm{~mL})$ was added and the mixture was centrifuged to separate the catalyst. The filtrate was concentrated and the crude solid product was recrystallized from ethanol to afford pure product.

\section{RESULTS AND DISCUSSION}

In order to study the optimization of reaction conditions, the synthesis of compound $3 \mathrm{~b}$ was chosen as a model reaction (Scheme 2, Table 1). Firstly, we examined the reaction using ethanol as a solvent. In a simple experimental procedure, to a mixture of 4-nitrobenzaldehyde $(1 \mathrm{mmol})$ and 4-hydroxycoumarin $(2 \mathrm{mmol})$ in ethanol $(5 \mathrm{~mL}), \mathrm{Ru} @ i m i n e-z(5 \mathrm{w} \%, 24$ $\mathrm{mg}$ ) was added and the resulting mixture was stirred under reflux condition for 25 minute, to give, after workup, a $80 \%$ yield of compound $3 \mathrm{~b}$ (Table 1, entry 1 ). To find out the optimum quantity of catalyst, the reaction was carried out under reflux conditions using different quantities of catalyst (Table 1, entries 2-4). It was found that the best results were obtained in the presence of 10 w\% of Ru@imine-Z (Table 1, entry 2). Larger amount of catalyst, however, had no significant effect on the yield. Conducting the same reaction, by using $20 \mathrm{w} \%(95 \mathrm{mg})$ of activated zeolite (Z-H), led to low yield of the desired product (25\%) after $2 \mathrm{~h}$ (Table 1, entry 5$)$. The effect of temperature was also studied by carrying out the model reaction in the presence of $10 \mathrm{w} \%$ of Ru@imine-Z at room temperature, which gave a $50 \%$ yield of the desired product after $24 \mathrm{hr}$ (Table 1, entry 6). To investigate the effect of solvent, the model reaction was accomplished in various solvents, such as ethanol, methanol, acetonitrile, tetrahydrofuran and dichloromethane at different reflux temperatures (Table 1, entries 7-10). As shown in Table 1, ethanol was chosen as the best solvent. Finally, the model reaction was carried out under homogeneous catalytic system which gave the corresponding products in high yields (Table 1, entries 11-12).

Using these optimized reaction conditions, the scope and efficiency of the reaction were explored for the synthesis of a wide variety of substituted biscoumarins. A series of aromatic and heterocyclic aldehydes were selected to undergo the condensation in the presence of Ru@imine-z. As shown in Table 2, aromatic aldehydes carrying either electron-donating or electron-withdrawing substituents reacted efficiently giving excellent yields (85-95\%) (Table 2, entries 2-17). It is also noteworthy that the electronic properties of the aromatic ring have an effect on the reaction time. The aromatic aldehydes bearing electron-withdrawing groups reacted somehow, faster than those bearing electron-releasing groups. Furthermore, heterocyclic aldehydes could react smoothly to give the corresponding products in good yields (85-92\%) (Table 2, entries 18-20). To improve efficiency, we carried out this reaction under ultrasonic irradiation. As it is shown in Table 2 , this method affords the desired products in excellent yields in rather short times. 
Table 1. Screening of the reaction conditions for the synthesis 3,3'-(4 nitrophenylmethylene)bis-(4-hydroxy-2Hchromen-2-one) (3b).

\begin{tabular}{|c|c|c|c|c|c|}
\hline Entry & Solvent & $\begin{array}{c}\text { Temp } \\
\left({ }^{\circ} \mathrm{C}\right)\end{array}$ & $\begin{array}{c}\text { Amount of catalyst (w\%) } \\
(\mathrm{min})\end{array}$ & Yield (\%) \\
\hline 1 & $\mathrm{EtOH}$ & 80 & 5 & 25 & 80 \\
\hline 2 & $\mathrm{EtOH}$ & 80 & 10 & 25 & 95 \\
\hline 3 & $\mathrm{EtOH}$ & 80 & 15 & 25 & 95 \\
\hline 4 & $\mathrm{EtOH}$ & 80 & 20 & 25 & 95 \\
\hline 5 & $\mathrm{EtOH}$ & 80 & 20 & 120 & $25^{\mathrm{a}}$ \\
\hline 6 & $\mathrm{EtOH}$ & r.t. & 10 & 1440 & $50^{\mathrm{b}}$ \\
\hline 7 & $\mathrm{MeOH}$ & 65 & 10 & 45 & 92 \\
\hline 8 & $\mathrm{CH}{ }_{3} \mathrm{CN}$ & 80 & 10 & 60 & 90 \\
\hline 9 & $\mathrm{THF}$ & 70 & 10 & 90 & 80 \\
\hline 10 & $\mathrm{CH}_{2} \mathrm{Cl}$ & 40 & 10 & 25 & $92^{\mathrm{c}}$ \\
\hline 11 & $\mathrm{EtOH}^{\mathrm{c}}$ & 80 & 5 & 25 & $90^{\mathrm{d}}$ \\
\hline 12 & $\mathrm{H}_{2} \mathrm{O}$ & 80 & 5 & 120 & 30 \\
\hline
\end{tabular}

${ }^{\mathrm{a}}$ Activated zeolite was used as a catalyst.

${ }^{\mathrm{b}}$ Reaction was accomplished at room temperature.

${ }^{c} \mathrm{Ru}_{3}(\mathrm{CO})_{12}(5 \mathrm{~mol} \%)$ was used as a homogeneous catalyst.

${ }^{d} \mathrm{RuCl}_{3} . n \mathrm{H}_{2} \mathrm{O}$ (5 mol \%) was used as a homogeneous catalyst.

According to the literatures [1-3], we think that heterogenized ruthenium catalyzes the reaction as a mild Lewis acid. The mechanism was tentatively proposed in scheme 3. As it is shown, prior activation of the carbonyl group of aldehyde by Ru to give intermediate I, followed by Knoevenagel condensation with 4-hydroxycoumarin provides unsaturated intermediate II. Michael addition of intermediate II with second molecule of 4-hydroxycoumarin and subsequent tautomeric proton shift affords the desired product (Scheme 3).

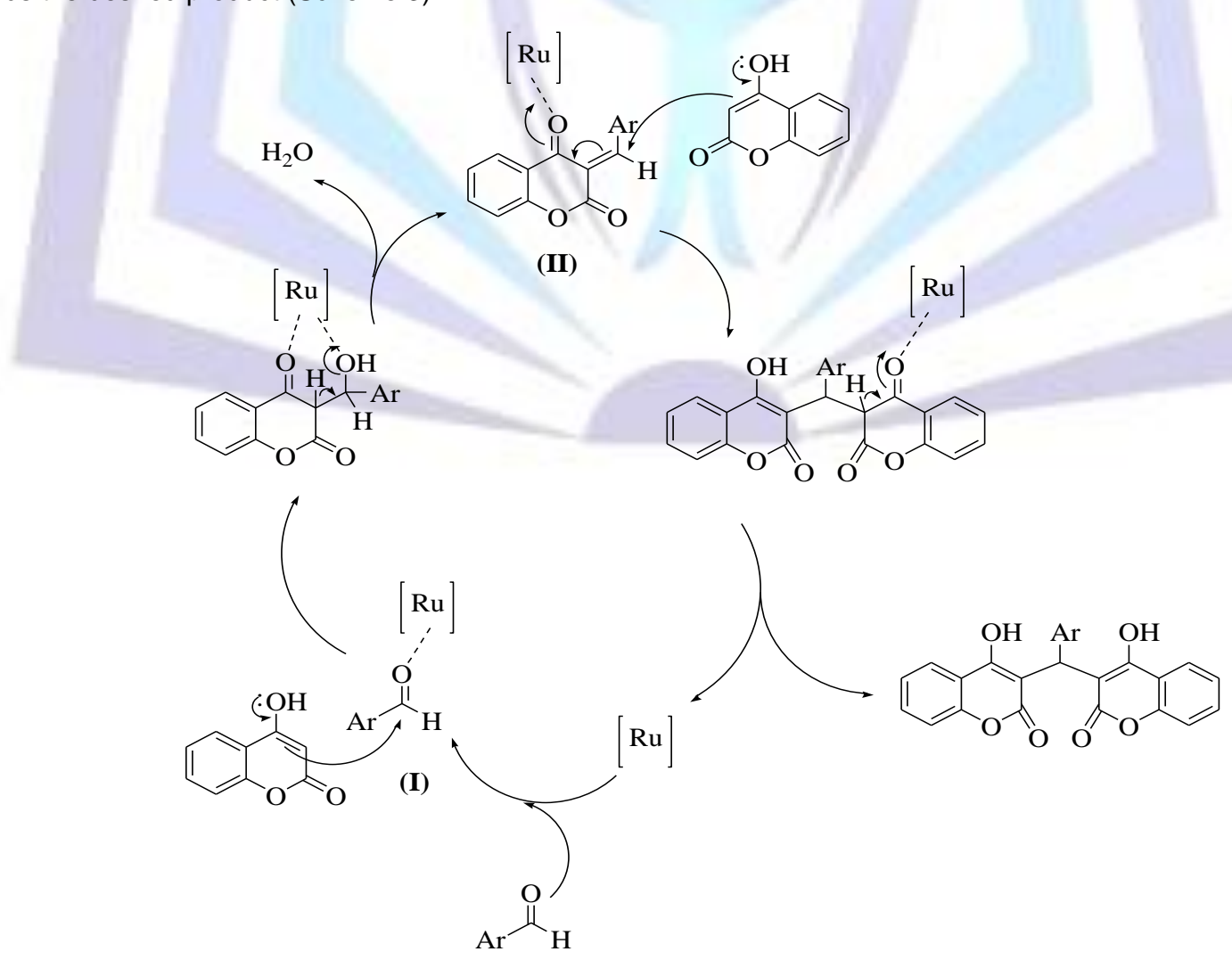

Scheme 3: Proposed mechanism for the synthesis of biscoumarins in the presence of Ru@imine-Z as catalyst 
Table 2. Synthesis of biscoumarins in the presence of Ru@imine-Z under reflux condition and ultrasonic irradiation.

\begin{tabular}{|c|c|c|c|c|c|c|c|c|}
\hline \multirow[t]{2}{*}{ Entry } & \multirow[t]{2}{*}{$\mathrm{Ar}$} & \multirow[t]{2}{*}{ Product } & \multicolumn{2}{|c|}{$\begin{array}{c}\text { Reflux } \\
\text { Condition }\end{array}$} & \multicolumn{2}{|c|}{$\begin{array}{l}\text { Ultrasonic } \\
\text { Irradiation }\end{array}$} & \multicolumn{2}{|c|}{ M.P. $\left({ }^{\circ} \mathrm{C}\right)$} \\
\hline & & & $\begin{array}{l}\text { Time } \\
(\min )\end{array}$ & $\begin{array}{c}\text { Yield }^{\mathrm{a}} \\
(\%)\end{array}$ & $\begin{array}{l}\text { Time } \\
\text { (min) }\end{array}$ & $\begin{array}{c}\text { Yield }^{\mathrm{a}} \\
(\%)\end{array}$ & Found & $\begin{array}{c}\text { Reported } \\
\text { [Ref.] }\end{array}$ \\
\hline 1 & $\mathrm{C}_{6} \mathrm{H}_{5}$ & $3 a$ & 30 & 90 & 5 & 92 & $213-215$ & 215 [38] \\
\hline 2 & $4-\mathrm{NO}_{2} \mathrm{C}_{6} \mathrm{H}_{4}$ & $3 b$ & 25 & 95 & 4 & 95 & $236-238$ & $238-239$ [39] \\
\hline 3 & $3-\mathrm{NO}_{2} \mathrm{C}_{6} \mathrm{H}_{4}$ & $3 c$ & 25 & 88 & 5 & 92 & $212-214$ & $212-215$ [38] \\
\hline 4 & $2-\mathrm{NO}_{2} \mathrm{C}_{6} \mathrm{H}_{4}$ & $3 d$ & 30 & 85 & 7 & 90 & $199-201$ & $198-200[34]$ \\
\hline 5 & $4-\mathrm{ClC}_{6} \mathrm{H}_{4}$ & $3 e$ & 20 & 92 & 4 & 95 & $260-262$ & $261-263[34]$ \\
\hline 6 & $3-\mathrm{ClC}_{6} \mathrm{H}_{4}$ & $3 f$ & 25 & 90 & 5 & 90 & $228-230$ & $228-230[31]$ \\
\hline 7 & $2-\mathrm{ClC}_{6} \mathrm{H}_{4}$ & $3 g$ & 25 & 88 & 5 & 90 & $202-204$ & $201-203$ [34] \\
\hline 8 & $4-\mathrm{FC}_{6} \mathrm{H}_{4}$ & $3 \mathrm{~h}$ & 20 & 90 & 4 & 97 & $214-216$ & $213-215$ [31] \\
\hline 9 & $3,4-\mathrm{F}_{2} \mathrm{C}_{6} \mathrm{H}_{3}$ & $3 i$ & 30 & 92 & 5 & 95 & $261-263$ & $262-264[40]$ \\
\hline 10 & $3-\mathrm{C}_{6} \mathrm{H}_{5} \mathrm{OC}_{6} \mathrm{H}_{4}$ & $3 j$ & 30 & 90 & 6 & 92 & $219-221$ & $218-220[40]$ \\
\hline 11 & $4-\mathrm{OHC}_{6} \mathrm{H}_{4}$ & $3 k$ & 25 & 90 & 5 & 92 & $221-223$ & $222-224$ [28] \\
\hline 12 & $2-\mathrm{OHC}_{6} \mathrm{H}_{4}$ & 31 & 30 & 85 & 6 & 88 & $252-254$ & $254-256[28]$ \\
\hline 13 & $4-\mathrm{CH}_{3} \mathrm{C}_{6} \mathrm{H}_{4}$ & $3 m$ & 35 & 90 & 4 & 90 & $268-270$ & $266-269$ [34] \\
\hline 14 & $4-\mathrm{CH}_{3} \mathrm{OC}_{6} \mathrm{H}_{4}$ & $3 n$ & 35 & 90 & 6 & 94 & $250-252$ & $250-252[34]$ \\
\hline 15 & $3,4-\left(\mathrm{CH}_{3} \mathrm{O}\right)_{2} \mathrm{C}_{6} \mathrm{H}_{3}$ & 30 & 40 & 85 & 8 & 90 & $267-269$ & $266.5-268$ [22] \\
\hline 16 & $4-\left(\mathrm{CH}_{3}\right)_{2} \mathrm{NC}_{6} \mathrm{H}_{4}$ & $3 p$ & 30 & 94 & 7 & 94 & $223-225$ & $222-224[31]$ \\
\hline 17 & $4-\mathrm{CH}_{3} \mathrm{SC}_{6} \mathrm{H}_{4}$ & $3 q$ & 20 & 88 & 8 & 90 & $259-260$ & $258-260[37]$ \\
\hline 18 & 5-Methyl-2-thiophenyl & $3 r$ & 30 & 92 & 7 & 95 & 350 & $>300[33]$ \\
\hline 19 & 3-Indolyl & $3 s$ & 40 & 85 & 7 & 92 & $238-240$ & $238-240[40]$ \\
\hline 20 & 4-pyridyl & $3 t$ & 25 & 90 & 5 & 90 & $252-254$ & $252-254$ [33] \\
\hline
\end{tabular}

Note: All products were characterized by ${ }^{1} \mathrm{H}$ NMR, ${ }^{13} \mathrm{C}$ NMR and IR data.

${ }^{a}$ Yields refer to isolated pure products.

To compare the efficiency of our catalyst with respect to the previously reported catalysts for the preparation of biscoumarins, the results for the synthesis of $3 \mathrm{~b}$ as a model compound, employing these catalysts, are tabulated in Table 3. As it is shown, zeolite supported ruthenium (Ru@imine-Z) acts as effective catalyst with respect to reaction time and yield of the product.

Table 3. Comparison of our results with those reported in the literature for the Synthesis of 3,3'-(4 nitrophenylmethylene)bis-(4-hydroxy-2H-chromen-2-one) (3b).

\begin{tabular}{|c|c|c|c|c|c|c|}
\hline Entry & Catalyst (amount) & Solvent & $\begin{array}{c}\text { Temp } \\
\left({ }^{\circ} \mathrm{C}\right)\end{array}$ & $\begin{array}{c}\text { Time } \\
(\mathrm{min})\end{array}$ & Yield (\%) & Ref. \\
\hline 1 & $\mathrm{SiO}_{2} \mathrm{Cl}(75 \mathrm{mg})$ & $\mathrm{CH}_{2} \mathrm{Cl}_{2}$ & 40 & 210 & 85 & 36 \\
\hline 2 & $\mathrm{SDS}(20$ mol\%) & $\mathrm{H}_{2} \mathrm{O}$ & 60 & 180 & 98 & 31 \\
\hline 3 & $\begin{array}{c}\mathrm{SO}_{3} \mathrm{H} \text {-functionalized ionic } \\
\text { liquids (10 mol\%) }\end{array}$ & - & 70 & 120 & 96 & 32 \\
\hline 4 & $\mathrm{TiO}_{2} / \mathrm{SO}_{4}{ }^{-2}(10 \mathrm{w} \%)$ & $\mathrm{H}_{2} \mathrm{O}$ & 80 & 30 & 88 & 35 \\
\hline 5 & $\mathrm{I}_{2}(10 \mathrm{~mol} \%)$ & $\mathrm{H}_{2} \mathrm{O}$ & 100 & 28 & 95 & 28 \\
\hline 6 & $\mathrm{TBAB}(10 \mathrm{~mol} \%)$ & $\mathrm{H}_{2} \mathrm{O}$ & 100 & 25 & 91 & 29 \\
\hline 7 & $\mathrm{RuCl} 3 . n \mathrm{H}_{2} \mathrm{O}(5 \mathrm{~mol} \%)$ & $\mathrm{H}_{2} \mathrm{O}$ & 80 & 25 & 90 & 40 \\
\hline 8 & $\mathrm{Ru@imine-z} \mathrm{(10} \mathrm{w \% )}$ & $\mathrm{EtOH}$ & 80 & 25 & 95 & - \\
\hline
\end{tabular}


The reusability of the catalyst was investigated in the synthesis of 3,3'-(4 nitrophenylmethylene)bis-(4-hydroxy-2Hchromen-2-one) (3b). The catalyst was separated after each run, washed thoroughly with ethyl acetate and acetone, dried in an oven at $60{ }^{\circ} \mathrm{C}$ and reused in subsequent runs. The recovered catalyst was reused in subsequent reactions without significant decrease in activity even after five runs (Table 4). Moreover, ICP analysis showed $20 \%$ decrease in the Ru content on the solid catalyst before and after five run use.

Table 4. Reusability of the catalyst for synthesis of compound $3 \mathrm{~b}$.

\begin{tabular}{|c|c|}
\hline Run No. & Yield (\%) \\
\hline 1 & 95 \\
\hline 2 & 92 \\
\hline 3 & 90 \\
\hline 4 & 88 \\
\hline 5 & 88 \\
\hline
\end{tabular}

\section{CONCLUSION}

In brief, we have introduced a simple strategy to heterogenize a homogeneous ruthenium complex onto zeolite beta. The resulted catalyst was applied in the synthesis of biscoumarin derivatives and the corresponding products were obtained in excellent yields. Moreover, our heterogeneous catalyst could retain high activity of the homogeneous counterpart catalyst.

\section{ACKNOWLEDGMENTS}

The authors are thankful to the Guilan University Research Council for the partial support of this work.

\section{REFERENCES}

[1] Murahashi, S. I. 2004. Ruthenium in Organic Synthesis, Wiley-VCH, New York.

[2] Bruneau, C., Dixneuf, P. H. 2004. Ruthenium Catalysts and Fine Chemistry, Springer, Berlin.

[3] Naota, T., Takaya, H., Murahashi, S. I. 1998. Ruthenium-catalyzed reactions for organic synthesis. Chem. Rev. 98, 2599-2660.

[4] Chen, P., Fan, B. B., Song, M. G., Jin, C., Ma, J. H., Li, R. F. 2006. Zeolite-encapsulated Ru(III) tetrahydro-Schiff base complex: An efficient heterogeneous catalyst for the hydrogenation of benzene under mild conditions. Catal. Commun. 7, 969-973.

[5] Aldea, R., Alper, H. 2000. Ruthenium clay catalyzed reduction of $\alpha$-iminoesters and $\alpha$-iminoketones, and the reductive amination of $\alpha$-ketoesters. J. Organomet. Chem. 593-594, 454-457.

[6] Miao, S., Liu, Z., Han, B., Huang, J., Sun, Z., Zhang, J., Jiang, T. 2006. Ru nanoparticles immobilized on montmorillonite by ionic liquids: A highly efficient heterogeneous catalyst for the hydrogenation of benzene. Angew. Chem. Int. Ed. 45, 266-269.

[7] Islam, S. M., Tuhina, K., Mubarak, M., Mondal, P. 2009. Hydrogenation of various organic substrates using polystyrene anchored orthometallated ruthenium (II) complex as catalyst. J. Mol. Catal. A: Chem. 297, 18-25.

[8] Kim, J. W., Yamaguchi, K., Mizuno, N. 2009. Heterogeneously catalyzed selective N-alkylation of aromatic and heteroaromatic amines with alcohols by a supported ruthenium hydroxide. J. Catal. 263, 205-208.

[9] Veerakumar, P., Lu, Z. Z., Velayudham, M., Lu, K. L., Rajagopal, S. 2010. Alumina supported nanoruthenium as efficient heterogeneous catalyst for the selective $\mathrm{H}_{2} \mathrm{O}_{2}$ oxidation of aliphatic and aromatic sulfides to sulfoxides. $\mathrm{J}$. Mol. Catal. A: Chem. 332, 128-137.

[10] Hatefi, M., Moghadam, M., Mirkhani, V., Sheikhshoaei, I. 2010. Silica supported Ru(salophen)Cl: An efficient and robust heterogeneous catalyst for epoxidation of alkenes with sodium periodate. Polyhedron 29, 2953-2958.

[11] Huang, X., Wu, H., Liao, X., Shi, B. 2010. Liquid phase hydrogenation of olefins using heterogenized ruthenium complexes as high active and reusable catalyst. Catal. Commun. 11, 487-492.

[12] Yen, C. H., Lin, H. W., Tan, C.-S. 2011. Hydrogenation of bisphenol A - Using a mesoporous silica based nano ruthenium catalyst Ru/MCM-41 and water as the solvent. Catal. Today 174, 121- 126.

[13] Khorshidi, A., Tabatabaeian, K. 2011. Ruthenium-exchanged FAU-Y zeolite catalyzed improvement in the synthesis of $6 \mathrm{H}$-indolo[2,3-b]quinolines. J. Mol. Catal. A: Chem. 344, 128-131.

[14] Lee, J. H., Bang, H. B., Han, S. Y., Jun, J. G. 2007. An efficient synthesis of (+)-decursinol from umbelliferone, Tetrahedron Lett. 48, 2889-2892. 
[15] Manian, R. D. R. S., Jayashankaran, J., Raghunathan, R. 2007. A rapid access to indolo[2,1a]pyrrolo[4',3':4,5]pyrano[5,6-c]coumarin/[6,5-c]chromone derivatives by domino Knoevenagal intramolecular hetero Diels-Alder reactions, Tetrahedron Lett. 48, 1385-1389.

[16] Zhao, H., Neamati, N., Hong, H., Mazumder, A., Wang, S., Sunder, S., Milne, G. W. A., Pommier, Y., Burke, T. R. 1997. Coumarin-based inhibitors of HIV integrase. J. Med. Chem. 40, $242-249$.

[17] Okenne, R., Thomes, R. D. 1997. Coumarins: Biology Application and Modes of Action, Wiley \& Sons, Chichester.

[18] Zahradnik, M. 1992. The Production and Application of Fluorescent Brightening Agents, Wiley \& Sons, Chichester.

[19] Murray, R. D. H. 1995. Coumarins. Nat. Prod. Rep. 12, 477-505.

[20] Franke, K., Porzel, A., Schmidt, J. 2002. Flavone-coumarin hybrids from gnidia socotrana. Phytochemistry 61, 873878.

[21] Liu, J., Feng, Z., Xu, J., Wang, Y., Zhang, P. 2007. Rare biscoumarins and a chlorogenic acid derivative from erycibe obtusifolia. Phytochemistry 68, 1775-1780.

[22] Manolov, I., Moessmer, C. M., Danchev, N. 2006. Synthesis, structure, toxicological and pharmacological investigations of 4-hydroxycoumarin derivatives. Eur. J. Med. Chem. 41, 882-890.

[23] Hamdi, N., Puerta, M. C., Valerga, P. 2008. Synthesis, structure, antimicrobial and antioxidant investigations of dicoumarol and related compounds. Eur. J. Med. Chem. 43, 2541-2548.

[24] Talhi, O., Schnekenburger, M., Panning, J., Pinto, D. G. C., Fernandes, J. A., Almeida Paz, F. A., Jacob, C., Diederich, M., Silva, A. M. S. 2014. Bis(4-hydroxy-2H-chromen-2-one): Synthesis and effects on leukemic cell lines proliferation and NF-KB regulation. Bioorg. Med. Chem. 22, 3008-3015.

[25] Choudhary, M. I., Fatima, N., Khan, K. M., Jalil, S., Iqbal, S., Rahman, A. U. 2006. New biscoumarin derivativescytotoxicity and enzyme inhibitory activities. Bioorg. Med. Chem. 14, 8066-8072.

[26] Khan, K. M., Iqbal, S., Lodhi, M. A., Maharvi, G. M., Ullah, Z., Choudhary, M. I., Rahman, A. U., Perveen, S. 2004. Biscoumarin: New class of urease inhibitors; Economical synthesis and activity. Bioorg. Med. Chem. 12, $1963-1968$.

[27] Kostova, I., Manolov, I., Nicolova, I., Konstantinov, S., Karaivanova, M. 2001. New lanthanide complexes of 4-methyl7-hydroxycoumarin and their pharmacological activity. Eur. J. Med. Chem. 36, 339-347.

[28] Kidwai, M., Bansal, V., Mothsra, P., Saxena, S., Somvanshi, R. K., Dey, S., Singh, T. P. 2007. Molecular iodine: A versatile catalyst for the synthesis of bis(4-hydroxycoumarin) methanes in water. J. Mol. Catal. A: Chem. 268, 76-81.

[29] Khurana, J. M., Kumar, S. 2009. Tetrabutylammonium bromide (TBAB): A neutral and efficient catalyst for the synthesis of biscoumarin and 3,4-dihydropyrano[c]chromene derivatives in water and solvent-free conditions. Tetrahedron Lett. 50, 4125-4127.

[30] Sangshetti, J. N., Kokare, N. D., Shinde, D. B. 2009. Water mediated efficient one-pot synthesis of bis-(4hydroxycoumarin)methanes, Green Chem. Lett. Rev. 2, 233-235.

[31] Mehrabi, H., Abusaidi, H. 2010. Synthesis of biscoumarin and 3,4-dihydropyrano[c]chromene derivatives catalysed by sodium dodecyl sulfate (SDS) in neat water. J. Iran. Chem. Soc. 7, 890-894.

[32] Li, W., Wang, Y., Wang, Z., Dai, L., Wang, Y. 2011. Novel $\mathrm{SO}_{3} \mathrm{H}$-functionalized ionic liquids based on benzimidazolium cation: Efficient and recyclable catalysts for one-pot synthesis of biscoumarin derivatives. Catal. Lett. 141, 1651-1658.

[33] Siddiqui, Z. N., Farooq, F. 2011. Zn(Proline) 2 : A novel catalyst for the synthesis of dicoumarols. Catal. Sci. Technol. 1, 810-816.

[34] Tavakoli-Hoseini, N., Heravi, M. M., Bamoharram, F. F., Davoodnia, A., Ghassemzadeh, M. 2011. An unexpected tetracyclic product isolated during the synthesis of biscoumarins catalyzed by $\left[\mathrm{MIM}\left(\mathrm{CH}_{2}\right)_{4} \mathrm{SO}_{3} \mathrm{H}\right]\left[\mathrm{HSO}_{4}\right]$ : Characterization and X-ray crystal structure of 7-(2-hydroxy-4-oxo-4H-chromen-3-yl)-6H,7H-chromeno[4,3b]chromen-6-one. J. Mol. Liqu. 163, 122-127.

[35] Karmakar, B., Nayak, A., Banerji, J. 2012. Sulfated titania catalyzed water mediated efficient synthesis of dicoumarols: A green approach. Tetrahedron Lett. 53, 4343-4346.

[36] Karimian, R., Piri, F., Safari, A. A., Davarpanah, S. J. 2013. One-pot and chemoselective synthesis of bis(4hydroxycoumarin) derivatives catalyzed by nano silica chloride. J. nanostructure chem. 3(52), 1-6.

[37] Shirini, F., Ranjbar, S. E., Seddighi, M. 2014. Poly(4-vinylpyridinium) perchlorate as an efficient and recyclable catalyst for the synthesis of biscoumarins and bisindoles. Chin. J. Catal. 35, 1017-1023.

[38] Qadir, S., Dar, A. A., Khan, K. Z. 2008. Synthesis of biscoumarins from 4-hydroxycoumarin and aromatic aldehydes: A comparative assessment of percentage yield under thermal and microwave-assisted conditions. Synth. Commun. 38, 3490-3499. 
[39] Gong, G. X., Zhou, J. F., An, L. T., Duan, X. L., Ji, S.-J. 2009. Catalyst-free synthesis of a,a-bis(4-hydroxycoumarin-3yl)toluene in aqueous media under microwave irradiation. Synth. Commun. 39, 497-505.

[40] Tabatabaeian, K., Heidari, H., Khorshidi, A., Mamaghani, M., Mahmoodi, N. O. 2012. Synthesis of biscoumarin derivatives by the reaction of aldehydes and 4-hydroxycoumarin using ruthenium(III) chloride hydrate as a versatile homogeneous catalyst. J. Serb. Chem. Soc. 77, 407-413.

[41] Tabatabaeian, K., Zanjanchi, M. A., Mamaghani, M., Dadashi, A. 2014. Anchoring of ruthenium onto iminefunctionalized zeolite beta: An efficient route for the synthesis of $4 \mathrm{H}$-benzo[b]pyrans and pyrano[c]chromenes. Can. J. Chem. 92, 1086-1091.

\section{Author' biography with Photo}

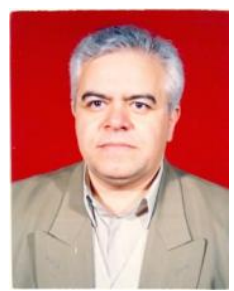

Khalil Tabatabaeian was born in Mashhad, Iran. He received his B.Sc in Pure Chemistry from Mashhad University, Iran in 1976. He started his doctoral studies in Sheffield University, England, and obtained his Ph.D. degree in 1980. He has been a faculty member of Guilan University since 1982 . His current research interest includes heterogenization of homogeneous catalysts, through covalent attachment to inorganic matrices such as zeolites and metal organic frameworks which combines the advantages of homogenous and heterogeneous catalysis. 